\title{
Susceptibility of Electronic Components and Equipment to HEMP: The Facts and Consequences
}

\author{
Vladimir Gurevich, Ph.D* \\ Central Electrical Laboratory Israel Electric Corp., Haifa, Israel
}

*Corresponding Author: Vladimir Gurevich, Central Electrical Laboratory Israel Electric Corp., Haifa, Israel

\begin{abstract}
Today, it is impossible to imagine that any part of the country's infrastructure operates without electronic equipment based on microprocessors and computers. This is especially true for critical systems such as power supply, water supply and sewage, communication and transportation networks. Modern electronic equipment uses lower level electrical signals, (compared to electrically powered equipment that was used in the beginning of the previous century or even electronic equipment of the previous generation that was based on electron vacuum tubes) and features much more difficult and branched internal architecture. This was the key for the sharp increase of modern electronic equipment's susceptibility to HighAltitude Electromagnetic Pulse (HEMP), and that of the entire country's infrastructure. What is the actual susceptibility of different electronic elements and devices that employ them to HEMP? How can we use this knowledge in practice? This article deals with the answers to these questions.
\end{abstract}

Keywords: HEMP, susceptibility of electronic equipment, integrated circuits, controllers, microprocessor, protection from EMP

\section{INTRODUCTION}

When analyzing the HEMP's impact onto the infrastructure, special emphasis is always placed on electronic equipment. For example, the comprehensive report of the US Congress Commission dealing with the HEMP's impact on critical parts of the country's infrastructure addresses primarily the issues of electronic equipment susceptibility. Indeed, the report begins with the analysis of susceptibility of such electronic systems. The first chapter of this multipage report is called "The SCADA system. Susceptibility of SCADA and its effect on critical infrastructure" [1]. Supervisory Control and Data Acquisition (SCADA) is a hardware and software package intended for real-time collection, processing, displaying and zipping of information in complex and branched systems of various purposes, the components of which are remotely located and autonomously operate automatically. These include power and water supply systems and etc.

According to the report, analysis of computers, local area networks and common use of the network hardware revealed that where the length of connection cables is $7-60$ meters, the magnitude of induced current can reach as high as $100-700 \mathrm{~A}$, causing inoperable computer equipment. The analysis revealed that multiple duplication and backing-up of equipment is not efficient, and that the volume of reasonable reserve does not correspond to the assortment of spare parts and that the number of operating units is not adequate.

The report also found that an electromagnetic pulse (EMP) impact can cause the majority of electronic equipment of civil communication and telecommunication systems to be inoperable. In this regard, mobile communication systems will be much more affected than the ordinary communication lines. Even weak EMP can lead to a several-day failure of mobile communication systems, whereas the ordinary lines will be out of order for several hours. These estimates were obtained based on the model of EMP damage and further recovery of mobile communication systems.

The report also assesses the EMP resistance of modern electrical locomotives, equipped with a microprocessor control system. The newer models have got three computers that control all the subsystems. Failure of any of them will cause the locomotive to stop. Malfunctioning of the locomotive's equipment starts at the EMP electric field's density of $4-8 \mathrm{kV} / \mathrm{m}$, whereas the outright failure occurs 
at $20-40 \mathrm{kV} / \mathrm{m}$. The Committee concluded that it takes several days or weeks to restore the railway service due to equipment repair, and several months in case it is necessary to substitute the damaged computer systems.

The testing of 37 cars manufactured in 1986 through 2002, and 18 trucks manufactured in 1991 through 2003, regarding the impact of standard HEMP with the field density of up to $50 \mathrm{kV} / \mathrm{m}$, revealed that approximately $10 \%$ of the vehicles will immediately be inoperable with emergency consequences at the electric field densities of $25-30 \mathrm{kV} / \mathrm{m}$ and higher. Traffic control centers will also become inoperable, thus making the situation in large cities even worse. Power outage will result in shutdown of the majority of traffic lights.

The list of disasters that can happen upon HEMP impact on the country's infrastructure can be continued. However, the specialists would, in our opinion, be more interested in addressing more specific issues at the level of the electronic equipment's hardware components, in order to understand the processes in running the electronic equipment and how it can be protected.

During the last 50 years there was much research devoted to HEMP susceptibility of various electronic components, as well as integral microchips, micro-processors, micro-controllers, computers and computer networks. Below are the findings of this research.

\section{SuSCEPTIBILITY OF DISCRETE ELECTRONIC COMPONENTS}

For discrete electronic components, such as diodes, transistors, capacitors, resistors, etc., the failure resulting upon the impact of an electromagnetic pulse is (though not always!) irreversible and attributable to the breakdown of their internal structure under the pulse of an applied reverse voltage, or that of a forward current exceeding specific threshold values.

The technical report written by the staff of the Air Force Research Laboratory [2] makes a profound analysis of different theoretical models of disruption of diodes and transistors' semi-conducting structure, discusses the limitations of various models and provides related critical judgments. Two major models enjoyed the spread: thermal (Wunsch-Bell model) and electro-thermal, (Ward model and Barush-Budenstein model) named after their authors. The report suggests that the thermal Wunsch-Bell model does not fully reflect physical processes running upon disruption of the semiconducting structure, in particular, in the case of nanoseconds, the attempts of using the Wunsch-Bell model are incorrect. However, the fact is that in the case of quick reduction of pulse power below a certain threshold limit, the semiconductor device can restore its functionality.

Thus, there can be two types of malfunctioning in semiconductor components and (which is even more important and relevant) electronic devices, i.e.: reversible (upset) and irreversible (destruction), see fig. 1.

In the case of an upset, there is no physical damage and destruction to the internal structure of a semiconductor device or a microchip, and its functionality can be fully restored automatically upon some certain delay without any intervention or manually after system reboot (with regard to a computer system).

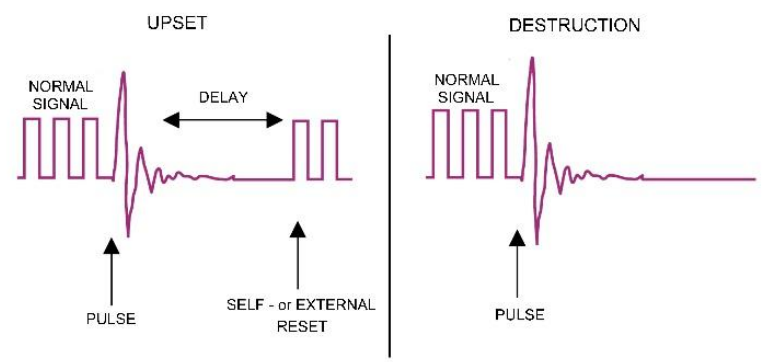

Figure1. Upset and destruction in semiconductor devices and their constituents under the external impact pulse.

The destruction results in physical damage of the semiconductor devices' internal structure, which is related to the damage to $p-n$ junctions (blowing) of a semiconductor structure, (see fig. 2) [3] or puncture of insulation between individual elements in the integrated system (see fig. 3) [4]. Upon destruction, the functionality of a device cannot be restored and thus the element (device) needs to be replaced. 

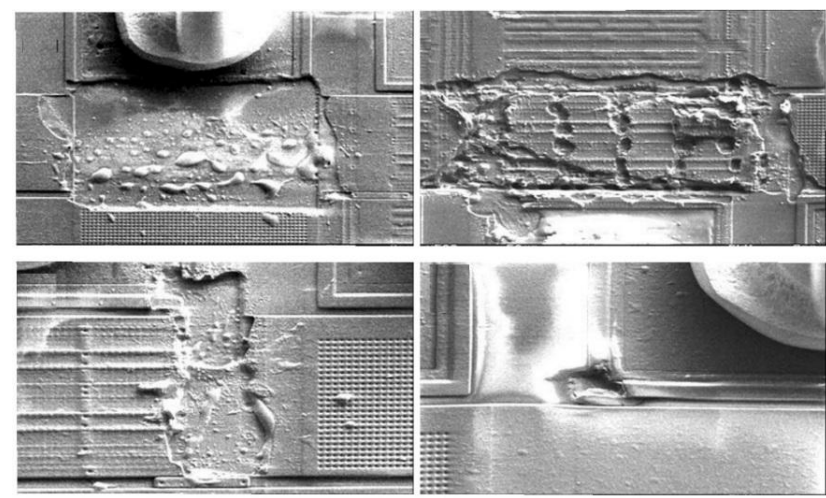

Figure2. Puncture and blowing of microprocessors' semiconductor structures as affected by the electromagnetic pulse of 7.5/180 nanoseconds (these pictures were taken using a microscope).

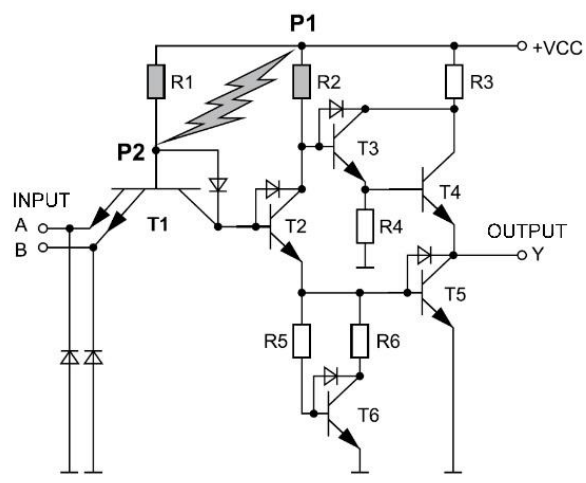

Figure3. Destruction of the 7400 series integral microchip (logical element AND-NO based on Schottky transistors) caused by the puncture between $P 1$ and $P 2$ points of the circuit and short-circuiting of R1 resistor.

In our opinion, theoretical arguments about an approximate description of what happens when a semiconductor structure of diodes and transistors fails, bear theoretical rather than practical interest, because the range of parameters obtained as a result of experiments, even for similar groups of diodes and transistors is so broad that they neglect the significance of arguments about the accuracy of different models. To confirm this, figure 4 shows experimental data obtained in [5] for a widely used general purpose bipolar transistor 2N2222, manufactured by many companies for dozens of years.

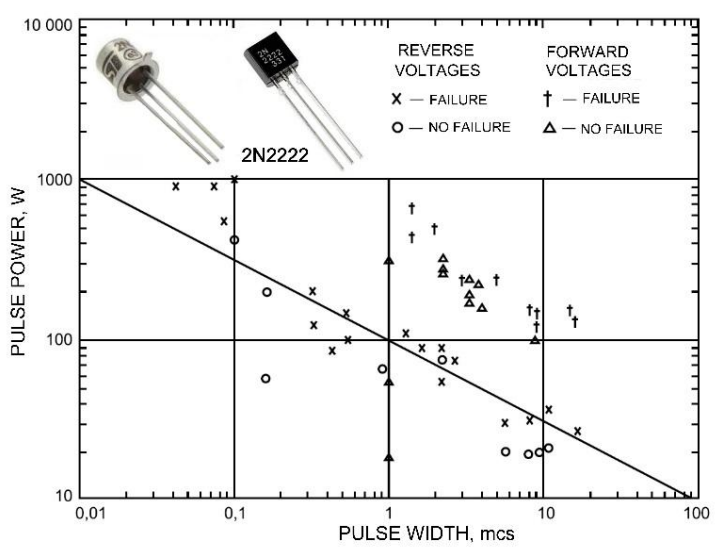

Figure4. Dispersion of destruction parameters of a group of 2N2222 transistors during the real-life testing.

Obviously, the accuracy of one or another theoretical model has no practical value with such significant dispersion of experimental data.

Nevertheless, the damage of semiconductor diodes and transistors is approximately associated with thermal processes and the damage of $p$ - $n$-junctions. Thus, it is obvious that the power of a pulse capable of damaging the semiconductor structure will depend on the duration (width) of this pulse. These dependencies, obtained experimentally for different types of semiconductor devices, are shown in fig. $3[5]$. 


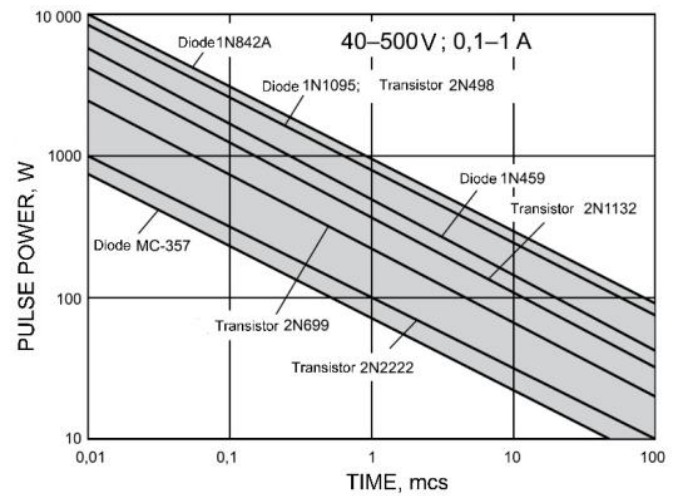

Figure5. Power of a destruction pulse as a function of its duration (for diodes and transistors with maximum operating voltage of 40 - $500 \mathrm{~V}$ and current rates of 0.1-1A).

It can be clearly seen that the area in fig. 5, where the damage of certain types of transistors or diodes takes place, is not a straight line, but rather a sort of an area containing many specifically scattered dots. These dots correspond to experimental data similarly to that shown in fig. 4. The straight lines represent averaged and generalized trends determined by these dots.

\section{SUSCEPTIBILITY OF INTEGRAL CIRCUITS (MicROCHIPS)}

For more complicated microelectronic elements, such as integral microchips, there are also upsets (fig. 6) [6], in addition to irreversible destructions that really occur frequently, unlike very rare upsets of discrete semiconductor elements.

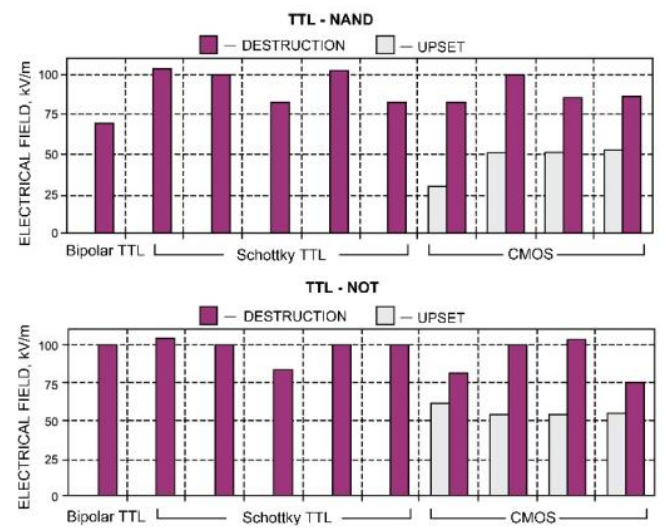

Figure6. Upsets and destructions of different types of logical microchips as affected by the pulse of external electric field.

It is interesting to note that the response of microchips with transistors built with CMOS technology (Complementary Metal-Oxide-Semiconductor) is completely different from that of microchips with bipolar transistors. Microchips based on bipolar transistors (unlike CMOS) rarely experience operating upsets; they are prone to immediate irreversible destructions (this feature of bipolar transistors was mentioned above).

The circuits on CMOS technology were invented by Frank Wanlass from Fairchild Semiconductor in 1963. Nowadays, the speed of switching, density of installation and energy consumption provided by CMOS technology are unattainable for technologies based on bipolar transistors. As a result, logical microchips based on CMOS transistors have almost completely displaced microchips based on bipolar transistors. Consequently, the upsets of microchips under the impact of external electric field are now more relevant as ever before.

A relatively high resilience of individual microchips to the pulse of an external electric field can be explained by small dimensions and small distances between the terminals. Smaller distances result in a relatively small potential difference occurring between conducting elements impacted by the pulse of an external electric field. However, considering that upon HEMP impact the external wires and cables connected to inputs of electronic devices (including microchips) will suffer high induced voltage applied directly to inputs and outputs of microchips, the situation becomes more serious. 
Table1. Parameters of destructing pulses applied to terminals of some types of microchips.

\begin{tabular}{|c|c|c|c|c|}
\hline \multirow{2}{*}{\multicolumn{2}{|c|}{$\begin{array}{l}\text { 8T15 LINE DRIVER } \\
\text { 8T16 RECEIVER }\end{array}$}} & \multicolumn{3}{|c|}{ PULSE WIDTHS } \\
\hline & & $25 \mathrm{~ns}$ & $100 \mathrm{~ns}$ & $1 \mathrm{mcs}$ \\
\hline \multirow{4}{*}{$\begin{array}{c}8 \mathrm{~T} 15 \\
\text { OUTPUTS }\end{array}$} & VOLTAGE, $V$ & 150 & 140 & 60 \\
\hline & CURRENT PULSE, A & 9 & 2 & 0,55 \\
\hline & POWER, W & 1350 & 280 & 33 \\
\hline & ENERGY, maJ & 33,7 & 28 & 33 \\
\hline \multirow{4}{*}{$\begin{array}{l}8 \mathrm{~T} 16 \\
\text { INPUT }\end{array}$} & VOLTAGE. $V$ & 220 & 175 & 125 \\
\hline & CURRENT PULSE, A & 1,5 & 0,8 & 0,14 \\
\hline & POWER, $W$ & 330 & 140 & 17,5 \\
\hline & ENERGY, maJ & 8,25 & 14 & 17,5 \\
\hline \multirow{2}{*}{\multicolumn{2}{|c|}{$\begin{array}{c}5404 \text { HEX INVERTER TTL } \\
\text { 54L30 NAND GATE TTL }\end{array}$}} & \multicolumn{3}{|c|}{ PULSE WIDTHS } \\
\hline & & $25 \mathrm{~ns}$ & 100 ns & $1 \mathrm{mcs}$ \\
\hline \multirow{4}{*}{5404} & VOLTAGE, V & 120 & 50 & 30 \\
\hline & CURRENT PULSE. A & 3 & 1 & 0,5 \\
\hline & POWER, W & 360 & 50 & 15 \\
\hline & ENERGY, mcJ & 9 & 5 & 15 \\
\hline \multirow{4}{*}{$54 \mathrm{~L} 30$} & VOLTAGE, V & 90 & 50 & 20 \\
\hline & CURRENT PULSE, A & 4 & 2 & 0,8 \\
\hline & POWER, W & 360 & 100 & 16 \\
\hline & ENERGY, mad & 9 & 10 & 16 \\
\hline \multirow{2}{*}{\multicolumn{2}{|c|}{ $\mu A 747$ LINEAR OP AMP }} & \multicolumn{3}{|c|}{ PULSE WIDTHS } \\
\hline & & $25 \mathrm{~ns}$ & $100 \mathrm{~ns}$ & $1 \mathrm{mcs}$ \\
\hline$\mu$ A747 INPUT & & \multicolumn{3}{|c|}{ NO FAILURES to $500 \mathrm{~V}$} \\
\hline \multirow{4}{*}{$\mu \mathrm{A} 747$ OUTPUT } & VOLTAGE, V & 65 & 100 & 200 \\
\hline & CURRENT PULSE, A & 6,5 & 9 & 12 \\
\hline & POWER, W & 422 & 900 & 2400 \\
\hline & ENERGY, Mad & 10,5 & 90 & 2400 \\
\hline \multicolumn{2}{|c|}{ MINIMUM VALUES } & \multicolumn{3}{|c|}{ PULSE WIDTHS } \\
\hline \multicolumn{2}{|c|}{ CMOS CD4000-SERIES } & $25 \mathrm{~ns}$ & $100 \mathrm{~ns}$ & 1 mos \\
\hline \multirow{4}{*}{ CD4001A } & VOLTAGE, $V$ & 350 & \begin{tabular}{|l|}
150 \\
\end{tabular} & 60 \\
\hline & CURRENT PULSE, A & 10 & 7 & 1,2 \\
\hline & POWER, $W$ & 3500 & 1050 & 72 \\
\hline & ENERGY, maJ & 87,5 & 105 & 72 \\
\hline \multirow{4}{*}{ CD4016 } & VOLTAGE, $V$ & 150 & 120 & 20 \\
\hline & CURRENT PULSE, A & 2 & 4 & 2 \\
\hline & POWER, W & 300 & 480 & 40 \\
\hline & 3N3RGY, maJ & 7,5 & 48 & 40 \\
\hline \multirow{4}{*}{ CD4049 } & VOLTAGE, V & 150 & 25 & 12 \\
\hline & CURRENT PULSE. A & 15 & 6 & 3 \\
\hline & POWER, $W$ & 2250 & 150 & 36 \\
\hline & ENERGY, maJ & 56,2 & 15 & 36 \\
\hline \multirow{4}{*}{ CD4050 } & VOLTAGE, $V$ & 170 & 60 & 20 \\
\hline & CURRENT PULSE, A & 13 & 7,5 & 3 \\
\hline & POWER, W & 2210 & 450 & 60 \\
\hline & 3N3RGY, mal & 55,2 & 45 & 60 \\
\hline \multirow{4}{*}{ CD4050 } & VOLTAGE.V & 120 & 60 & 24 \\
\hline & CURRENT PULSE, A & 4 & 4 & 2 \\
\hline & POWER, W & 480 & 240 & 48 \\
\hline & ENERGY, maJ & 12 & 24 & 48 \\
\hline & VOLTAGE, $V$ & 80 & 150 & 250 \\
\hline CD4071 & CURRENT PULSE, A & 5,2 & 0,3 & 0,4 \\
\hline & POWER: W & 416 & 45 & 100 \\
\hline & 3N3RGY, mad & 10,4 & 4,5 & 100 \\
\hline
\end{tabular}

Table 1 [7] shows the data regarding destruction of different microchips upon direct application of voltage to their inputs. During those trials, the amplitude and duration of applied pulses changed, and these values were fixed. Other parameters (current, power, energy) were not strictly fixed and were dependent on the amplitude of applied voltage and duration of pulses. Their values were obtained as a result of measurements. 
The above data suggests that damages of microchips occur at relatively low voltage, much lower than the real values that can occur under HEMP impact in the absence of an adequate protection from pulse overvoltage. Moreover, it should be noted that susceptibility of microchips to the pulse of an applied voltage decreases with the increase of pulse duration.

As shown in [8], dispersion of parameters responsible for the damage of semiconductor devices under the impact of short voltage pulses is stipulated by the log-normal distribution (see fig. 7).
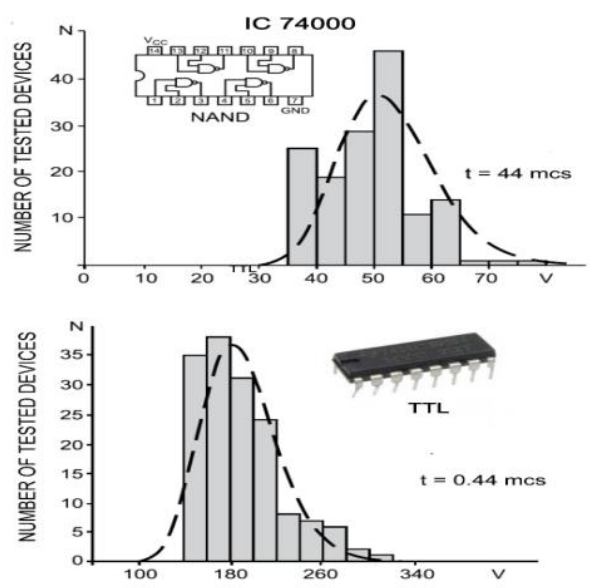

Figure7. Log-normal distribution of damage of 7400 type microchips caused by voltage pulse lasting for 44 and 0.44 microseconds.

This is the case when pulse voltage is directly applied to the microchip's terminals. Figure 7 shows that the voltage withstands the microchip before the damage significantly increases with the decrease of pulse duration, which is in agreement with the data from fig. 5 and table 1. However, fig. 7 also shows that the dispersion of the damaging voltage level is rather broad. Moreover, this dispersion relates to a microchip of the same type.

\section{SUSCEPTIBILITY OF MICROPROCESSORS}

Microprocessors have a much lower electric strength. The development of electronics follows a trend of continues reduction in the size of separate elements, increase of density of internal arrangement and complexity of integral circuits and microprocessors, reduction of insulation layers and, consequently, reduction of operating voltage. A good description of this trend is given in the Moor Law [9], which was elaborated by one of the founders of Intel Company Gordon Moor in 1965. According to the law, the number of transistors in microprocessors doubles every other year, whereas their capacity grows exponentially (fig. 8). This law has now been in effect for decades.

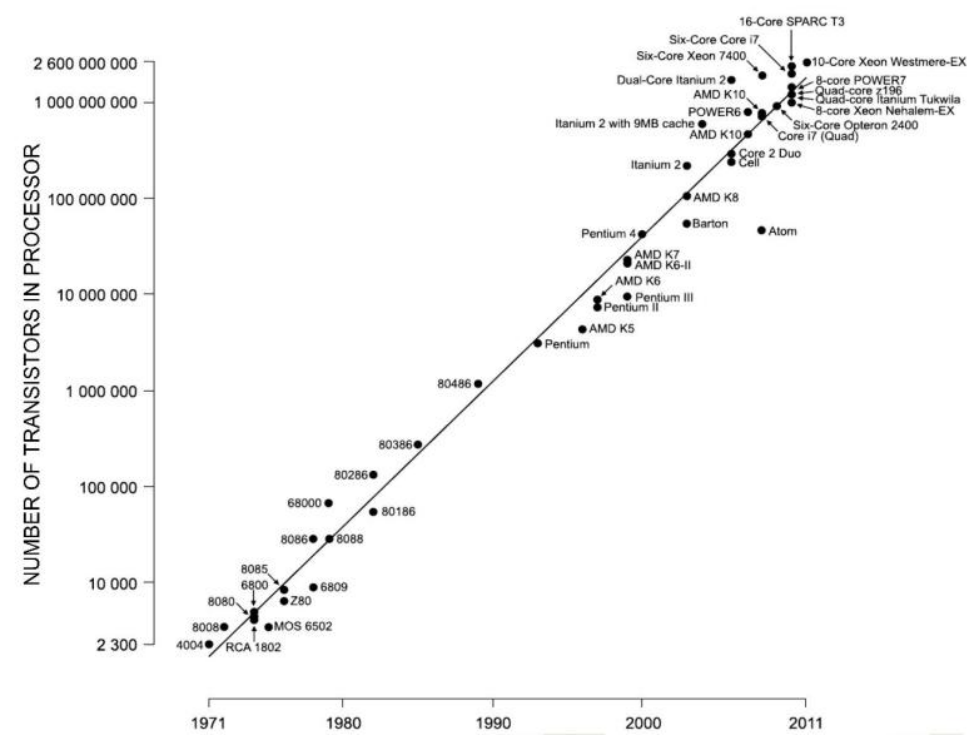

Figure8. Increase in the number of transistors on the microprocessor chip during the last 40 years. There is a logarithmic scale on the vertical axis, thus a straight line corresponds to the exponential law.

International Journal of Research Studies in Electrical and Electronics Engineering (IJRSEEE) Page 6 
See fig. 9 and fig. 10 concerning more detailed information on microprocessors up to Pentium III level [3].

\begin{tabular}{|c|c|c|c|c|}
\hline $\begin{array}{l}\text { PROCESSOR } \\
\text { (INTEL) }\end{array}$ & $\begin{array}{l}\text { CLOCK } \\
\text { RATE } \\
\text { MHz }\end{array}$ & 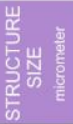 & 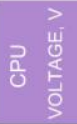 & 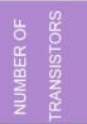 \\
\hline 8088 & 5 & $>1,5$ & 12 & 28000 \\
\hline 80286 & 10 & 1,5 & 5 & 130000 \\
\hline $80386 \mathrm{DX} 20$ & 20 & 1,5 & 5 & 275000 \\
\hline $80486 \mathrm{D} \times 25$ & 25 & 1 & 5 & 1200000 \\
\hline $80486 \mathrm{DX} 33$ & 33 & 1 & 5 & 1200000 \\
\hline P80486DX266 & 66 & 0,6 & 5 & 1200000 \\
\hline Pentium I & 75 & 0,6 & 3,3 & 3300000 \\
\hline Pentium I & 100 & 0,6 & 3,3 & 3300000 \\
\hline Pentium MMX & 200 & 0,35 & 2,8 & 4500000 \\
\hline Pentium II & 266 & 0,28 & 2,5 & 7500000 \\
\hline Pentium III & 450 & 0,25 & 2 & 9500000 \\
\hline Pentium III & 500 & 0,18 & 2 & 28000000 \\
\hline
\end{tabular}

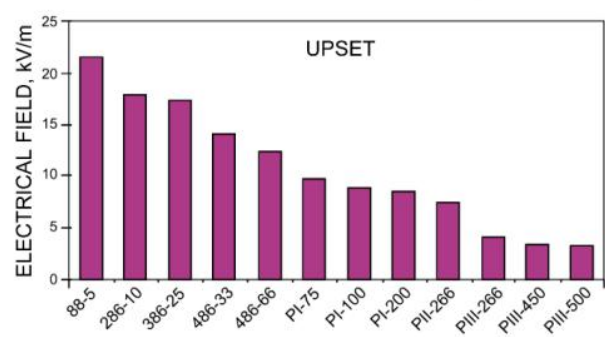

Figure9. Information on microprocessors (up to Pentium III inclusive) and the levels of pulse electric field resulting in their malfunctions.

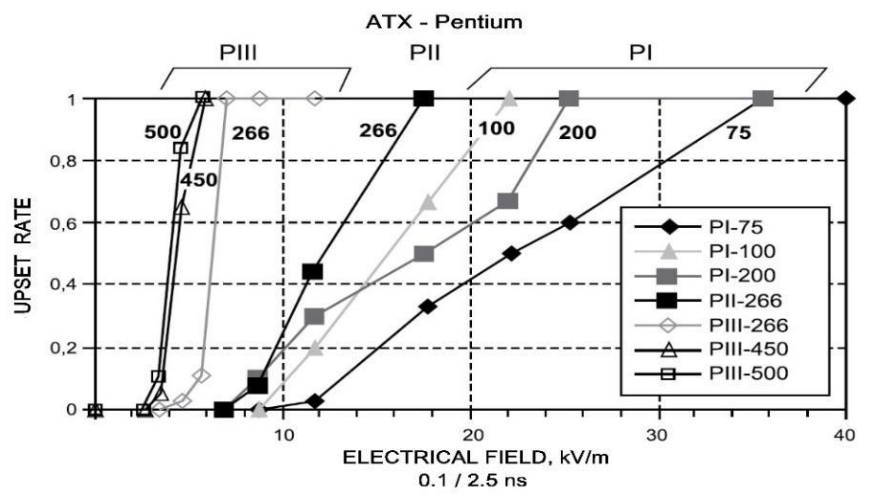

Figure10. The probability of microprocessor upsets when converting from older generation to newer generation.

For comparison, microprocessor Intel Pentium IV HT 661, B1 data: operating frequency $3.600 \mathrm{MHz}$, power voltage $1.25 \mathrm{~V}$ at structure size 0.065 microns (structure size determines the minimum size of the elements that can be shaped on a semiconductor plate during the photolithography process, which lies at the foundation of the microprocessor production). This high density of elements per a unit of the chip's area leads to tremendous heat production and, consequently, necessitates the use of an especially efficient cooling system. Obviously, this and related limitations may soon slow down the continuous growth of the transistors' number and violation of the Moor Law. However, today's level of placement density, (which affects the insulation distance between the elements) and the level of supply voltage and operating frequency are self-evident: susceptibility of modern microprocessors to HEMP has become much higher than it was 20-30 years ago.

Further research showed that susceptibility of microprocessors to electromagnetic pulse depends significantly on the pulse's frequency specifications (fig. 11) [3]. Figure 11 shows that a microprocessor's susceptibility to a short pulse with a high rise time (which is more typical for an ultra-wide band (UWB) pulse, generated by special directed sources of emission rather than for a wider HEMP pulse with a clearly lower rise time) is much higher. Regardless of lower energy of a UWB pulse, the efficiency of its impact (in terms of energy and voltage) onto a typical electronic system proves to be higher. The first upsets in case of a UWB pulse occur at field density of $12 \mathrm{kV} / \mathrm{m}$, whereas in case of HEMP, this happens at $30 \mathrm{kV} / \mathrm{m}$.

International Journal of Research Studies in Electrical and Electronics Engineering (IJRSEEE) Page | 7 


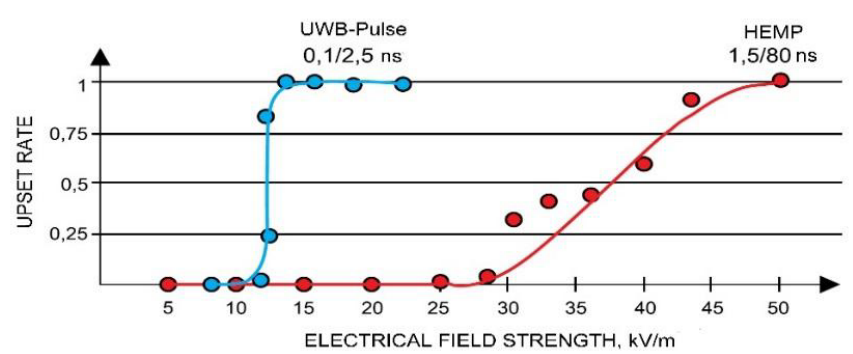

Figure11. Probability of upsets of Rocky-518 HV circuit board with a Pentium-MMX $233 \mathrm{MHz}$ processor as a function of different frequency specifications of a pulse.

Based on the above [3], it is concluded that the measure of induced energy is not the total energy of a pulse, but the energy in a certain frequency range.

\section{SUSCEPTIBILITY OF COMPUTERS}

Complex systems based on microprocessors, such as computers, are even more susceptible to HEMP. However, when testing free-standing personal computers equipped with a standard metal casing acting as a rather efficient shield, which is intended to weaken the external electromagnetic field, very high values for pulse amplitude in this field were obtained in [3], which caused destructions (fig. 12).

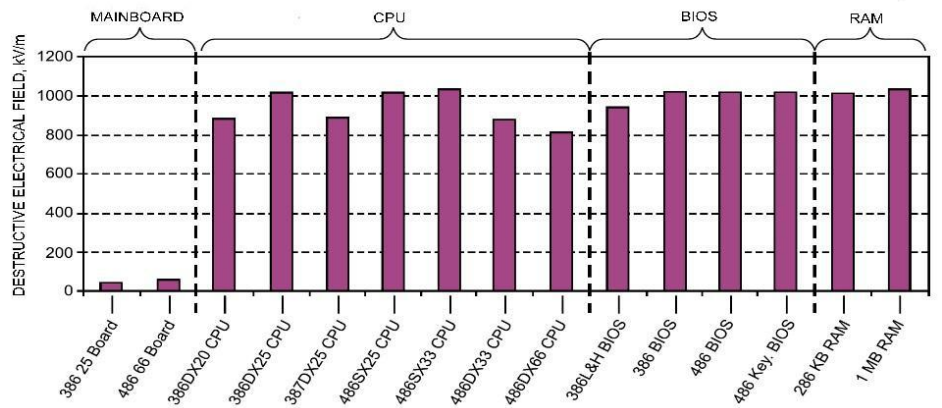

Figure12. Pulse amplitudes of damaging electric field (7.5/180 nsec) for different parts of PC

The motherboard is much larger than some elements of a computer. Thus, the potential difference occurring on the motherboard under the pulse impact of an external electric field is much higher than that between the inputs and outputs of smaller elements.

It is clear that the situation between a free-standing and shielded PC and a computer network, with its long communication cables, will be completely different (fig. 13) [3].

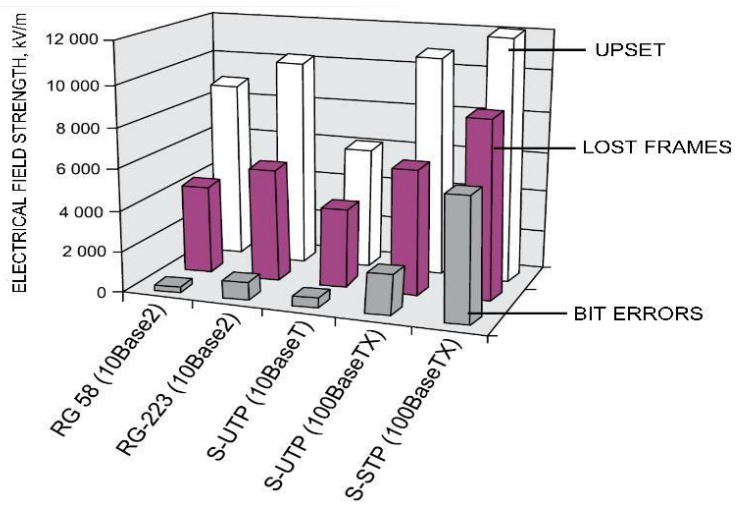

Figure13. The level of susceptibility (failures) of the simplest computer network for various network and cables configurations.

\section{CONCLUSION}

The above analysis shows that susceptibility of electronic equipment to HEMP is significantly dependent both on dispersion of the components' parameters (even of the same type) and on the variability of external conditions and impacting parameters of a pulse. This means that it is absolutely impossible to forecast the susceptibility level of electronic equipment under a real nuclear explosion 
situation. There is another conclusion that can be made: real testing of a certain type of electronic equipment on a test-bench, modeling HEMP, can be applied with their findings interpreted for a specific test sample only. They cannot be applied for similar units of other types, no matter how similar they are to the one being tested in terms of parameters and functionality.

Another conclusion that can be drawn, based on the above mentioned analysis, is that resistance of individual electronic components to a pulse of an external electric field is very high, much higher than the real field of HEMP. The problem is that this field induces a significant voltage in the long wires and cables, and since they are connected to the electronic equipment, they pose a serious danger. Thus, the efforts on protection of electronic equipment from HEMP should be aimed at prevention of high voltage pulse coming directly into it via connected cables.

\section{REFERENCES}

[1] Report of the Commission to Assess the Threat to the United States from Electromagnetic Pulse (EMP) Attack. Critical National Infrastructures. 2008.

[2] Yee J. H., Orvis W. J. Martin L. C. Theoretical Modeling of EMP Effects in Semiconductor Junction Devices. - Report AFWL-TR-82-91, Air Force Weapon Laboratory, Kirtland Air Force Base, 1983.

[3] Camp M., Garbe H. Susceptibility of Personal Computer Systems to Fast Transient Electromagnetic Pulses. - IEEE Transactions on Electromagnetic Compatibility, 2006, Vol. 48, No. 4, pp. 829 - 833.

[4] Camp M., Garbe H., Nitsh D. Influence of the Technology on the Destruction Effects of Semiconductors by Impact of EMP and UWB Pulses. - IEEE International Symposium on Electromagnetic Compatibility, 19 - 23 Aug. 2002, Minneapolis, USA, pp. $87-92$.

[5] Wunsch D. C., Bell B. R. Determination Failure Levels of Semiconductor Diodes and Transistors Due to Pulse Voltages. - IEEE Transactions on Nuclear Science, 1968, Vol. 15, issue 6, pp. 244 - 259.

[6] Nitsh D., Camp M., Sabath F.,Haseborg J. L., Garbe H. Susceptibility of Some Electronic Equipment to HPEM Threats. - IEEE Transactions on Electromagnetic Compatibility, 2004, Vol. 46, No. 3, pp. 380 389.

[7] Van Keuren E. Effects of EMP Induced Transients on Integrated Circuits. - IEEE International Symposium on Electromagnetic Compatibility, 7 - 9 Oct., 1975, San Antonio, TX, USA.

[8] Jenkins C. R., Durgin D. L. An Evaluation of IC EMP Failure Statistic. - IEEE Transactions on Nuclear Science, 1977, Vol. 24, No. 6, pp. $2361-2364$.

[9] Moore G. E. Cramming More Components onto Integrated Circuits. - "Electronics”, April 19, 1965, pp. 114-117.

\section{AUTHOR'S BIOGRAPHY}

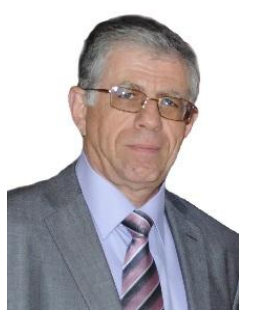

Vladimir I. Gurevich, was born in Kharkov, Ukraine, in 1956. He received an M.S.E.E. degree (1978) at the Kharkov Technical University, named after P. Vasilenko, and a Ph.D. degree (1986) at Kharkov National Polytechnic University.

His employment experience includes: teacher, assistant professor and associate professor at Kharkov Technical University, and chief engineer and director of Inventor, Ltd.

In 1994, he arrived in Israel and works today at Israel Electric Corp. as a senior specialist and Head of section of the Central Electric Laboratory.

He is the author of more than 200 professional papers and 13 books and holder of nearly 120 patents in the field of electrical engineering and power electronics. In 2006 he was Honorable Professor with the Kharkov Technical University.

Citation: Vladimir Gurevich. "Susceptibility of Electronic Components and Equipment to HEMP: The Facts and Consequences", International Journal of Research Studies in Electrical and Electronics Engineering, 4(2), pp 1-9. DOI: http://dx.doi. org/10.20431/2454-9436.0402001

Copyright: (C) 2018 Vladimir Gurevich. This is an open-access article distributed under the terms of the Creative Commons Attribution License, which permits unrestricted use, distribution, and reproduction in any medium, provided the original author and source are credited. 